Article

\title{
Low-Dissipation Thermosets Derived from Oligo(2,6-Dimethyl Phenylene Oxide)-Containing Benzoxazines
}

\author{
Chien-Han Chen ${ }^{1}$, Kuan-Wei Lee ${ }^{1}$, Ching-Hsuan Lin ${ }^{1, *}$ and Tzong-Yuan Juang ${ }^{2}$ \\ 1 Department of Chemical Engineering, National Chung Hsing University, Taichung 402, Taiwan; \\ jain6792002@gmail.com (C.-H.C.); tgdyt547165@gmail.com (K.-W.L.) \\ 2 Department of Cosmeceutics, China Medical University, Taichung 404, Taiwan; tyjuang@mail.cmu.edu.tw \\ * Correspondence: linch@nchu.edu.tw; Tel.: +886-4-22850180; Fax: +886-4-22854734
}

Received: 14 March 2018; Accepted: 2 April 2018; Published: 7 April 2018

\begin{abstract}
Poly(2,6-dimethyl phenyl oxide) (PPO) is known for its low dissipation factor. To achieve insulating materials with low dissipation factors for high-frequency communication applications, a telechelic oligomer-type benzoxazine (P-APPO) and a main-chain type benzoxazine polymer (BPA-APPO) were prepared from an amine end-capped oligo (2,6-dimethyl phenylene oxide) (APPO). The APPO was prepared from a nucleophilic substitution of a phenol-end capped oligo (2,6-dimethyl phenylene oxide) (a commercial product, SA 90) with fluoronitrobenzene, and followed by catalytic hydrogenation. After self-curing or curing with a dicyclopentadiene-phenol epoxy (HP 7200), thermosets with high- $T_{\mathrm{g}}$ and low-dissipation factor can be achieved. Furthermore, the resulting epoxy thermosets show better thermal and dielectric properties than those of epoxy thermoset cured from its precursor SA90, demonstrating it is a successful modification in simultaneously enhancing the thermal and dielectric properties.
\end{abstract}

Keywords: benzoxazine; low-dissipation; poly(phenyl oxide)

\section{Introduction}

The dielectric loss $(L)$ is proportional to the product of square root of dielectric constant $\left(D_{\mathrm{k}}^{1 / 2}\right)$, frequency, and dissipation factor $\left(D_{\mathrm{f}}\right)$. Therefore, the dielectric loss will be more obvious for application in high-frequency communication. In addition, $D_{\mathrm{f}}$ will be more important than $D_{\mathrm{k}}$ since $D_{\mathrm{f}}$ is directly proportional the $L$, while there is only a square root relationship between $D_{\mathrm{k}}$ and $L$.

Polybenzoxazines feature for special characteristics such as a moderate-to-high thermal property [1-18], moderate electrical property [19], low water absorption [20], and low surface energy [21]. Low-dielectric benzoxazines have been reported (1) by Chang et al. through Mannich condensation of bisphenol F/4-(trifluoromethyl)aniline/formaldehyde [22]; (2) by Liu et al. through incorporation of methyl methacrylate-POSS (MMA-POSS) into the network of bis(3-furfuryl-3,4dihydro-2H-1,3-benzoxazinyl)isopropane (BPA-FBz), which has furfuryl moiety that can react with methyl methacrylate through the Diels-Alder reaction [23]; (3) by Liu et al. through the incorporation of a benzobisoxazole structure [24,25]; (4) by Alagar et al. through the incorporation of silica (SBA-15) [26]; (5) by Ishida et al. from a highly fluorinated diamine and bisphenol F [27]; and (6) by Lin et al. from fluorinated aromatic diamine [28]. However, to the best of our knowledge, no data show that thermosets of these benzoxazines can reach the requirement of low dissipation factor below $0.005 \mathrm{U}$ for application in high-frequency communication.

Poly(2,6-dimethyl phenylene oxide) (PPO) is a hydrophobic polymer developed by Hay et al. through the aromatic oxidative polymerization $[29,30]$. PPO is known for its low dissipation factor. 
Therefore, $\mathrm{PPO}$ is a building block to prepare low-dissipation materials. Thermosetting low-dielectric PPOs have been reported by Ueda et al. [31,32]. Low-molecular-weight telechelic PPOs have been developed by White et al. [33-35], Jayakannan et al. [36], and Percec et al. [37], Telechelic PPO oligomers with phenyl methacrylate end group has been commercialized by SABIC in the name of NORYL ${ }^{\mathrm{TM}}$ SA9000 resin. Vinyl benzyl ether-terminated PPO has been commercialized by Mitsubishi Gas Chemical in the name of OPE-2st.

Difunctional benzoxazines are generally prepared by Mannich condensation of biphenol/monoamine/formaldehyde. Figure 1 shows the structure of SA90, a phenolic hydroxyl-end capped oligo (2,6-dimethyl phenylene oxide), commercialized by SABIC. The end group of SA90 is the 2,6-dimethyl phenolic $\mathrm{OH}$, which does not contain free ortho, so it cannot carry out the Mannich condensation with primary amine and formaldehyde directly. In addition to the Mannich condensation of biphenol/monoamine/formaldehyde, difunctional benzoxazines can also be prepared from the Mannich condensation of diamine/monophenol/formaldehyde. Therefore, the only way to prepare PPO-containing benzoxazines is transforming the phenolic hydroxyls to amino groups. In this work, an amine end-capped oligo (2,6-dimethyl phenylene oxide) (APPO, Figure 1) was prepared from a nucleophilic substitution of SA90 and fluoronitrobenzene, and followed by catalytic hydrogenation.

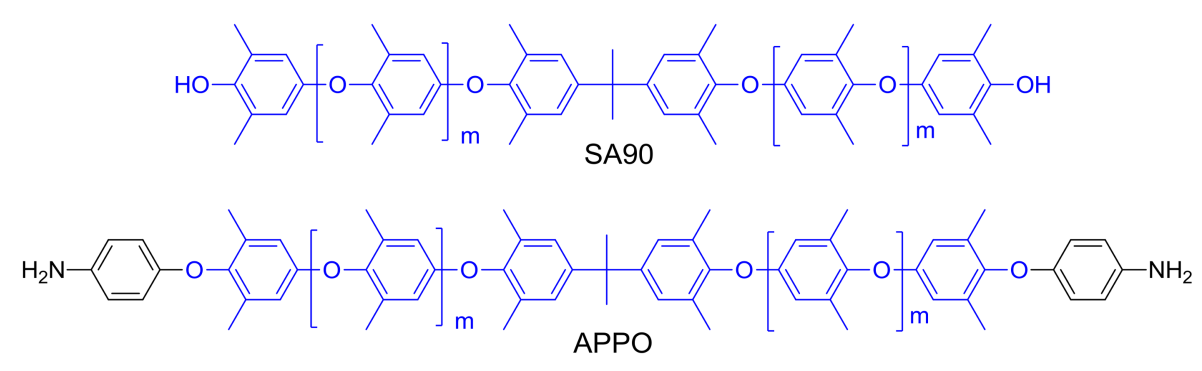

Figure 1. Structures SA90 and APPO. Note that there are no free ortho for SA90.

With APPO in hand, a telechelic oligomer-type benzoxazine from phenol, APPO, and formaldehyde was prepared by two approaches. The first approach is through a two-pot procedure to obtain the benzoxazine (P-APPO-2) [38]. The second approach is a one-pot Mannich condensation of phenol/APPO/formaldehyde to obtain the benzoxazine (P-APPO-1). A main-chain type benzoxazine polymer (BPA-APPO) was also prepared from the Mannich condensation of bisphenol $\mathrm{A} / \mathrm{APPO} /$ formaldehyde using the mixed solvent approach [39]. Experimental data show that thermosets with very low dissipation factors can be achieved. Detailed synthesis, characterization, and the property are provided in this work.

\section{Experimental Section}

\subsection{Materials}

NORYL ${ }^{\text {TM }}$ SA90 (the weight average molecular weight $1700 \mathrm{~g} / \mathrm{mol}$, and the number average molecular weight $1600 \mathrm{~g} / \mathrm{mol}$ ) was purchased from SABIC (Riyadh, Saudi Arabia). Dicyclopentadiene novolac epoxy (HP7200) with an epoxy equivalent per weight (EEW) of $250 \mathrm{~g} /$ eq was kindly supplied by Dainippon Ink and Chemicals Corporation (Tokyo, Japan). Potassium carbonate (from Showa, Tokyo, Japan), 4-fluoro-1-nitrobenzene (from Alfa, Heysham, England), bisphenol A (from Acros, NJ, USA), paraformaldehyde (from TCI, Tokyo, Japan), 2-hydroxybenzaldehyde (from Showa), sodium borohydride (from Alfa), phenol (from Showa), palladium on carbon 10\% (from Acros), and 4-dimethylaminopyrdine (DMAP, from Alfa) were purchased from various commercial sources and used without further purification. N-methylpyrrolidone (NMP; HPLC grade from Showa) and $\mathrm{N}, \mathrm{N}$-dimethyl acetamide (DMAc, HPLC grade from Showa) were purified by distillation under reduced 
pressure over calcium hydride (from Acros), and stored over molecular sieves. The other solvents (HPLC grade) were purchased from various commercial sources and used without further purification.

\subsection{Characterization}

Thermogravimetric analysis (TGA) was performed with a Perkin-Elmer Pyris1 (Perkin-Elmer, Shelton, CT, USA) at a heating rate of $20^{\circ} \mathrm{C} / \mathrm{min}$ in an atmosphere of nitrogen or air atmosphere. Dynamic mechanical analysis (DMA) was performed using a Perkin-Elmer Pyris Diamond DMA (Perkin-Elmer, Shelton, CT, USA) with a sample size of $5.0 \mathrm{~cm} \times 1.0 \mathrm{~cm} \times 0.2 \mathrm{~cm}$. The storage modulus $E^{\prime}$ and $\tan \delta$ were determined as the sample was subjected to the temperature scan mode at a programmed heating rate of $5{ }^{\circ} \mathrm{C} / \mathrm{min}$ at a frequency of $1 \mathrm{~Hz}$. The test was performed using a bending mode with an amplitude of $5 \mu \mathrm{m}$. $T_{\mathrm{g}}$ value is determined from the peak temperature of the tan $\delta$ curve. Dielectric properties were performed with Agilent E4991A (Agilent, Santa Clara, CA, USA) at $1 \mathrm{GHz}$ at $25{ }^{\circ} \mathrm{C}$. The sample size is $2 \times 2 \mathrm{~cm}^{2}$ with thickness at around $300 \mu \mathrm{m}$. Thermal mechanical analysis (TMA) was performed by an SII TMA/SS6100 (Seiko, Torrance, CA, US) at a heating rate of $5{ }^{\circ} \mathrm{C} / \mathrm{min}$. The coefficient of thermal expansion (CTE) was determined in the range of 50 to $150{ }^{\circ} \mathrm{C} . T_{\mathrm{g}}$ value is determined from onset temperature. NMR measurements were performed using a Varian Inova 600 NMR (Agilent, Palo Alto, CA, USA) in DMSO- $d_{6}$, and the chemical shift was calibrated by setting the chemical shift of DMSO- $d_{6}$ at $2.49 \mathrm{ppm}$. IR spectra were obtained from at least 32 scans in the standard wavenumber range of $667-4000 \mathrm{~cm}^{-1}$ using a Perkin-Elmer RX1 infrared spectrophotometer (Perkin-Elmer, Shelton, CT, USA). Gel permeation chromatography (GPC) was performed by a Hitachi L2400 (Hitachi, NY, USA) in Tetrahydrofuran (THF), using polystyrene as a standard.

\subsection{Synthesis of Nitro End-Capped Oligo (2,6-Dimethyl Phenylene Oxide) (NPPO)}

SA90 $10.0 \mathrm{~g}$ (6.2 mmol), 4-fluoro-1-nitrobenzene $2.62 \mathrm{~g}(18.6 \mathrm{mmol}), \mathrm{K}_{2} \mathrm{CO}_{3} 2.57 \mathrm{~g}(18.6 \mathrm{mmol})$, and DMAc $50 \mathrm{~mL}$ were introduced into a $250 \mathrm{~mL}$ round-bottom glass flask equipped with a nitrogen inlet, condenser, and a magnetic stirrer. The solution was stirred at $80^{\circ} \mathrm{C}$ for $24 \mathrm{~h}$ (Scheme 1). After that, the solution was poured into methanol/water $=1 / 1$, yielding green powder. After drying the powder at $70{ }^{\circ} \mathrm{C}$, the isolated yield was $91 \%$.

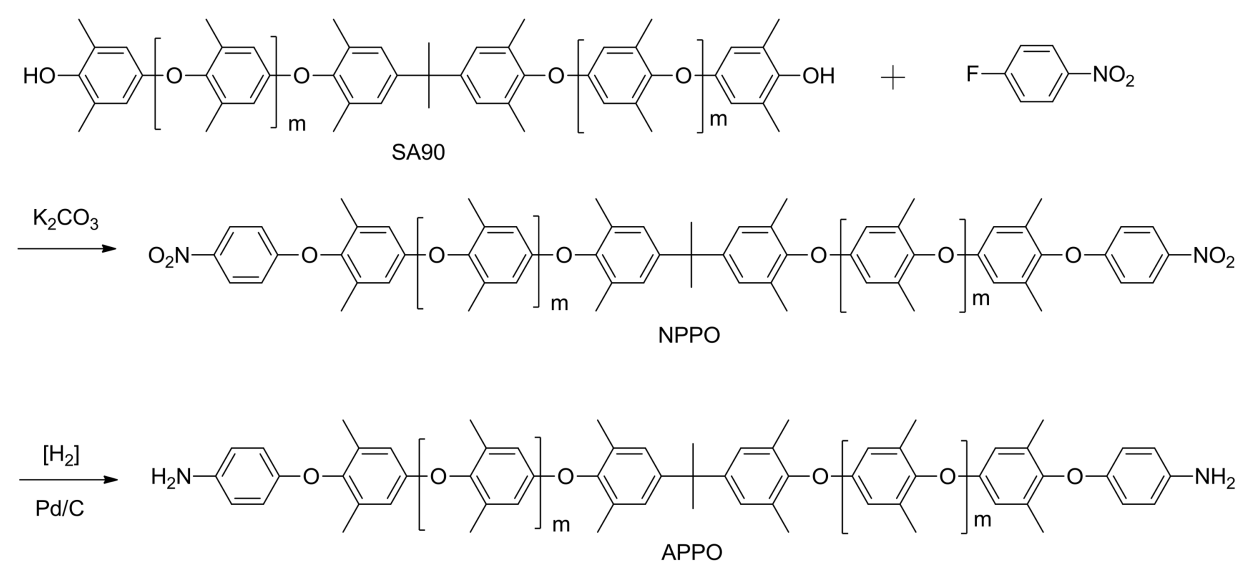

Scheme 1. Syntheis of NPPO and APPO.

\subsection{Synthesis of Amine End-Capped Oligo (2,6-Dimethyl Phenylene Oxide) (APPO)}

NPPO $10.0 \mathrm{~g}$ ( $6.2 \mathrm{mmol}), \mathrm{Pd} / \mathrm{C} 0.04 \mathrm{~g}$, and THF $40 \mathrm{~mL}$ were introduced into a $250 \mathrm{~mL}$ Parr reactor. The solution was stirred hydrogen atmosphere at $25^{\circ} \mathrm{C}, 140 \mathrm{psi}$ for $24 \mathrm{~h}$ (Scheme 1). After that, the solution was poured into methanol, yielding gray powder. After drying the powder at $70{ }^{\circ} \mathrm{C}$, the isolated yield was $93 \%$. 


\subsection{Two-Pot Synthesis of Telechelic Oligomer-Type Benzoxazine (P-APPO-2)}

2-Hydroxybenzaldehyde $0.22 \mathrm{~g}(1.68 \mathrm{mmol})$, APPO $1.0 \mathrm{~g}(0.56 \mathrm{~mol})$ and DMAc $10 \mathrm{~mL}$ were introduced into a $100-\mathrm{mL}$ round bottom glass flask equipped with a nitrogen inlet and a magnetic stirrer. The reaction mixture was stirred at room temperature for $12 \mathrm{~h} . \mathrm{NaBH}_{4} 0.066 \mathrm{~g}(1.68 \mathrm{mmol})$ was added and the solution was further stirred at room temperature for $24 \mathrm{~h}$ (Scheme 2). After that, the solution was poured into methanol/water $=1 / 1$, yielding intermediate II with gray color. After drying the powder at $70{ }^{\circ} \mathrm{C}$, the isolated yield was $93 \%$.

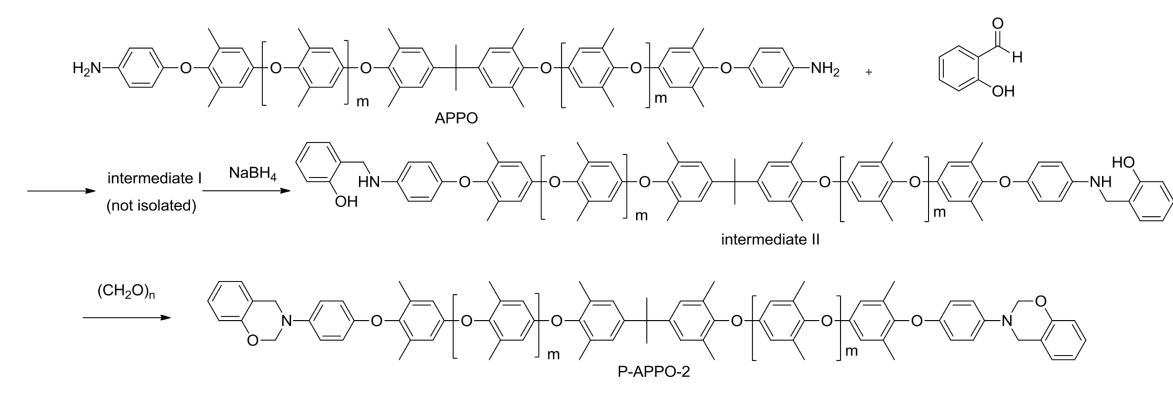

Scheme 2. Two-pot synthesis of telechelic oligomer-type benzoxazine (P-APPO-2).

$1.0 \mathrm{~g}$ ( $5.6 \mathrm{mmol})$ of intermediate II, paraformaldehyde $0.052 \mathrm{~g}(1.68 \mathrm{mmol})$, and toluene $5 \mathrm{~mL}$ were introduced into a 100-mL round bottom glass flask equipped with a condenser and a magnetic stirrer. The solution was stirred at $60{ }^{\circ} \mathrm{C}$ for $12 \mathrm{~h}$. After that, the solution was poured into methanol, yielding a green powder. After drying the powder at $70{ }^{\circ} \mathrm{C}$, the isolated yield was $93 \%$.

\subsection{One-Pot Synthesis of Telechelic Oligomer-Type Benzoxazine (P-APPO-1)}

APPO $2.0 \mathrm{~g}(0.56 \mathrm{mmol})$, phenol $0.32 \mathrm{~g}(1.68 \mathrm{mmol})$, paraformaldehyde $0.224 \mathrm{~g}(2.24 \mathrm{mmol})$, and toluène/ethanol (2/1) $30 \mathrm{~mL}$ were introduced into a $250 \mathrm{~mL}$ round bottom glass flask equipped with a condenser and a magnetic stirrer. The mixture was stirred at $80^{\circ} \mathrm{C}$ for $24 \mathrm{~h}$ (Scheme 3). After that, the solution was poured into methanol, yielding a green powder. After drying the powder at $70{ }^{\circ} \mathrm{C}$, the isolated yield was $91 \%$.

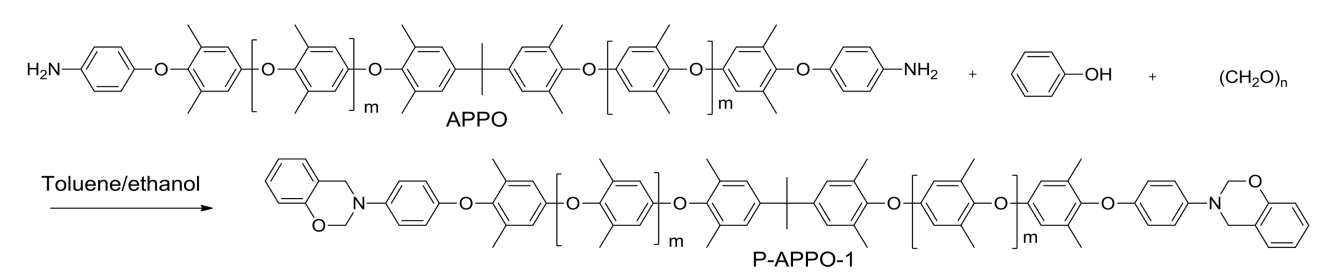

Scheme 3. One-pot synthesis of telechelic oligomer-type benzoxazine (P-APPO-1).

\subsection{Syntheis of Main-Chain Type Benzoxazine Polymer (BPA-APPO)}

APPO $2.0 \mathrm{~g}(0.56 \mathrm{mmol})$, biphenol A $0.26 \mathrm{~g}(0.56 \mathrm{mmol})$, paraformaldehyde $0.14 \mathrm{~g}(2.24 \mathrm{mmol})$, and toluene/ethanol (2/1) $22 \mathrm{~mL}$ were introduced into a $250 \mathrm{~mL}$ round bottom glass flask equipped with a condenser and a magnetic stirrer. The mixture was stirred at $80^{\circ} \mathrm{C}$ for $24 \mathrm{~h}$ (Scheme 4 ). After that, the solution was poured into methanol, yielding a gray powder. After drying the powder at $70{ }^{\circ} \mathrm{C}$, the isolated yield was $93 \%$. 


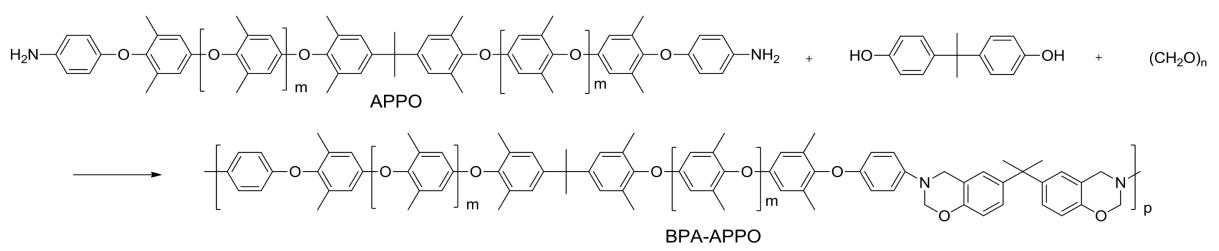

Scheme 4. Synthesis of main-chain type benzoxazine polymer (BPA-APPO).

\subsection{Sample Preparation and Curing Procedure}

\subsubsection{The Self-Curing of P-APPO-2, P-APPO-1, and BPA-APPO}

P-APPO-2, P-APPO-1, and BPA-APPO were thermally self-curing. Each benzoxazine was dissolved in xylene to make a solution with $20 \mathrm{wt} \%$ solid content. The solution was cast on a glass with an automatic film applicator. The resulting thin films were dried at $80^{\circ} \mathrm{C}$ for $12 \mathrm{~h}$. Then, cured by the program of $180{ }^{\circ} \mathrm{C}(2 \mathrm{~h}), 200{ }^{\circ} \mathrm{C}(2 \mathrm{~h})$, and $220^{\circ} \mathrm{C}(2 \mathrm{~h})$ under a nitrogen atmosphere. The thermosets are named C-P-APPO-2, C-P-APPO-1, and C-BPA-APPO, respectively

\subsubsection{The Co-Curing of HP7200 with P-APPO-2, P-APPO-1, and BPA-APPO}

P-APPO-2, P-APPO-1, and BPA-APPO were thermally co-curing with epoxy HP7200. The molar ratio of the oxazine moiety to oxirane (epoxy group) was controlled at one (The major curing reaction is the ring-opened phenolic OHs react with epoxy. The lone-pair electrons of nitrogen in oxazine act as the catalyst). Each benzoxazine and HP7200 were dissolved in xylene to make a solution with $20 \mathrm{wt} \%$ solid content. The solution was cast on a glass with an automatic film applicator. The resulting thin films were dried at $80{ }^{\circ} \mathrm{C}$ for $12 \mathrm{~h}$. Then, cured by the program of $180{ }^{\circ} \mathrm{C}(2 \mathrm{~h}), 200{ }^{\circ} \mathrm{C}(2 \mathrm{~h})$, and $220^{\circ} \mathrm{C}(2 \mathrm{~h})$ under a nitrogen atmosphere. The thermosets are named E-P-APPO-2, E-P-APPO-1, and E-BPA-APPO, respectively

\subsubsection{The Co-Curing of HP7200 with SA90}

For property comparison, SA90 was thermally co-curing with epoxy HP7200. The molar ratio of the phenolic OH moiety to oxirane (epoxy group) was controlled at one. SA90 and HP7200 were dissolved in xylene to make a solution with $20 \mathrm{wt} \%$ solid content. The solution was cast on a glass with an automatic film applicator. The resulting thin film was dried at $80^{\circ} \mathrm{C}$ for $12 \mathrm{~h}$. Then, cured by the program of $180{ }^{\circ} \mathrm{C}(2 \mathrm{~h}), 200{ }^{\circ} \mathrm{C}(2 \mathrm{~h})$, and $220^{\circ} \mathrm{C}(2 \mathrm{~h})$ under a nitrogen atmosphere. The thermoset is named E-SA90.

\section{Results and Discussion}

\subsection{Synthesis and Characterization of APPO}

APPO was prepared from the nucleophilic substitution of SA90 and fluoronitrobenzene, forming NPPO, and followed by catalytic hydrogenation of NPPO (Scheme 1). Figure 2 shows the ${ }^{1} \mathrm{H}-\mathrm{NMR}$ spectra of (a) SA90, (b) NPPO, and (c) APPO. The signals of phenolic $\mathrm{OH}$ at 7.8-8.0 ppm were observed in SA90. However, no phenolic $\mathrm{OH}$ signals were observed for NPPO, suggesting the completion of the reaction. The signals of $\mathrm{Ar}-\mathrm{H}$ ortho to the nitro group were observed at $8.2 \mathrm{ppm}$ for NPPO, while the signal disappeared in APPO. Furthermore, an amino peak at $4.6 \mathrm{ppm}$ was clearly observed for APPO, indicating the successful hydrogenation. Figure 3 shows the IR spectra of SA90, NPPO, and APPO. The absorption of phenolic $\mathrm{OH}$ at around $3600 \mathrm{~cm}^{-1}$ was observed in SA90. However, no phenolic $\mathrm{OH}$ signals were observed for NPPO, suggesting the completion of the reaction. The absorptions of the nitro group were observed at 1340 and $1518 \mathrm{~cm}^{-1}$, while the signal disappeared in APPO. Furthermore, two amino absorptions at 3455 and $3365 \mathrm{~cm}^{-1}$ were clearly observed, indicating the successful hydrogenation. 


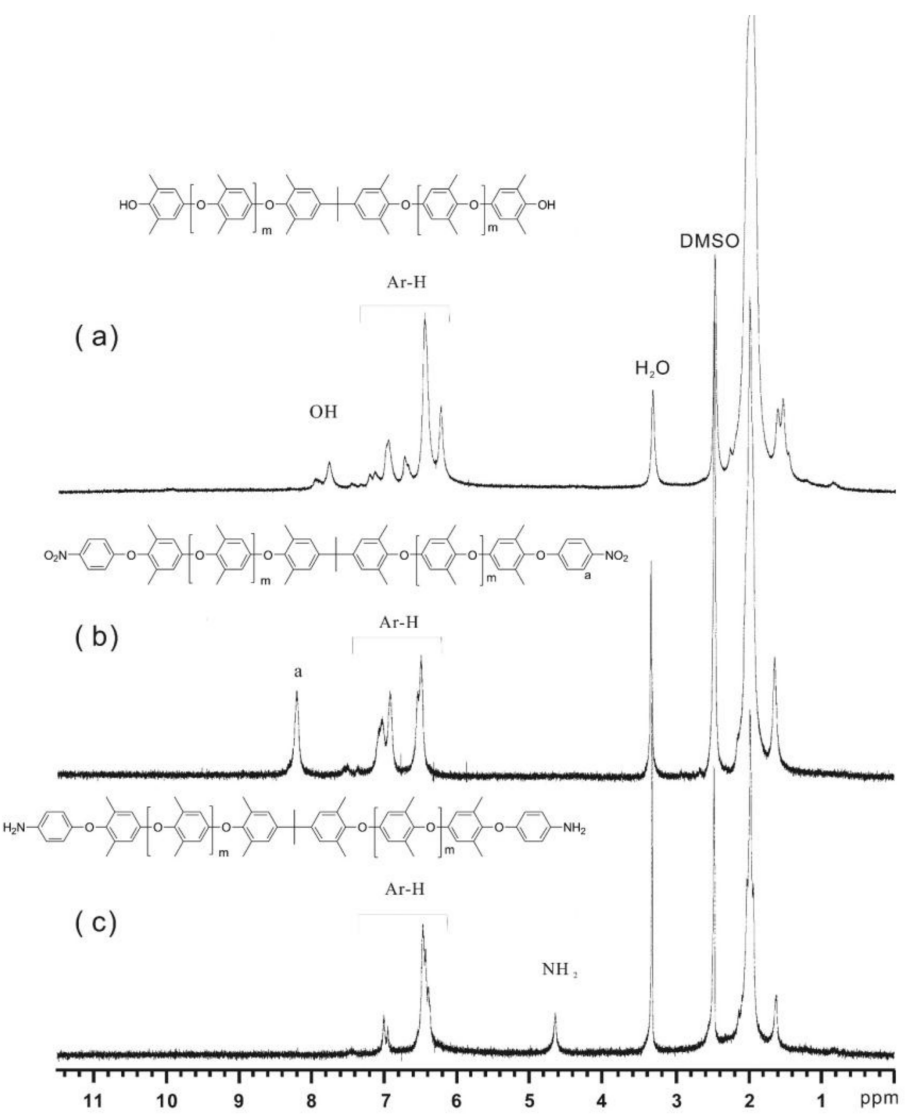

Figure 2. ${ }^{1} \mathrm{H}-\mathrm{NMR}$ spectra of (a) SA90, (b) NPPO, and (c) APPO in DMSO- $d_{6}$.

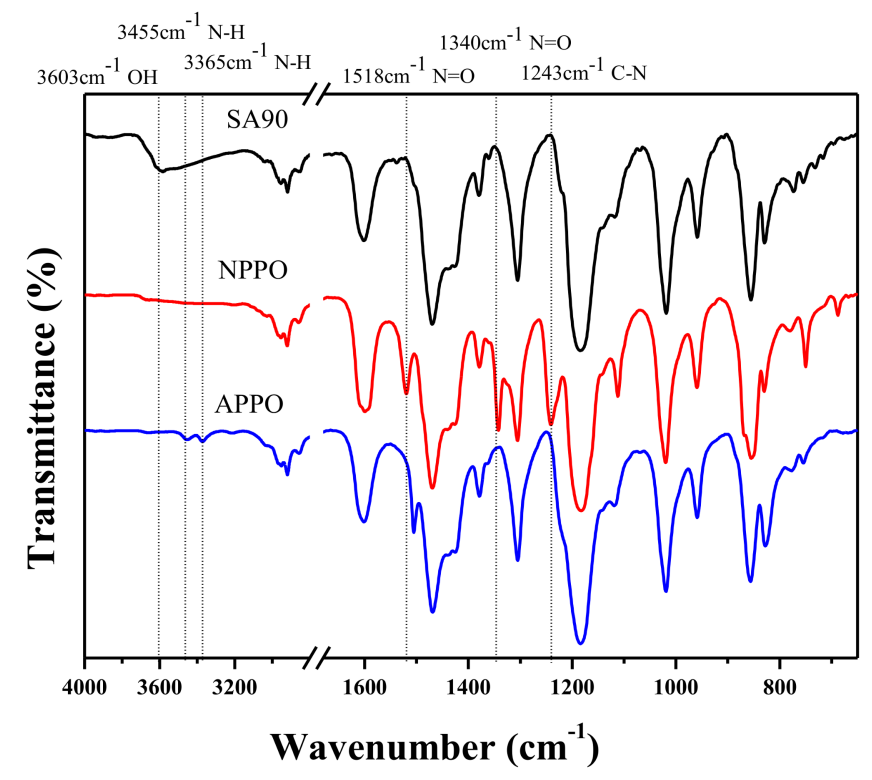

Figure 3. IR spectra of SA90, NPPO, and APPO.

\subsection{Synthesis and Characterization of Benzoxazine P-APPO}

The phenol/APPO-based benzoxazine was prepared by two procedures in this work. The first approach is a two-pot procedure (Scheme 2) [38]. The procedure includes the reaction of 2-hydroxybenzaldehyde and APPO, yielding intermediate I (not isolated) with an o-hydroxy 
phenylimine linkage. The imine linkage of intermediate I was reduced by sodium borohydride, yielding intermediate II with a secondary amine structure. Then, paraformaldehyde was added to induce the ring closure of intermediate II, forming P-APPO-2. Figure 4 shows the ${ }^{1} \mathrm{H}-\mathrm{NMR}$ spectra of (a) intermediate II, and (b) P-APPO-2. A phenolic OH signal at $9.5 \mathrm{ppm}$ and two new signals at 5.6 $(\mathrm{NH})$ and $4.1\left(\mathrm{CH}_{2}-\mathrm{NH}\right)$ confirm the structure of intermediate II. The characteristic peaks of oxazine at 5.3 and $4.6 \mathrm{ppm}$ confirm the formation of benzoxazine. No signal corresponding to $\mathrm{N}-\mathrm{CH}_{2}-\mathrm{Ph}$ at around $3.80 \mathrm{ppm}$ resulting from the ring-opened structure was observed, revealing the purity of synthesized P-APPO-2. The second approach is one-pot, Mannich condensation of phenol, APPO, and paraformaldehyde (Scheme 3). Using a traditional solvent such as dioxane leads to gelation. However, P-APPO-1 can be successfully prepared using a mixed solvent of toluene/ethanol, which is recommended in our previous work [39]. Figure 4c shows the ${ }^{1} \mathrm{H}-\mathrm{NMR}$ spectrum of P-APPO-1. The characteristic peaks of oxazine at 5.3 and $4.6 \mathrm{ppm}$ confirm the formation of benzoxazines. However, a small unknown peak was observed at $4.3 \mathrm{ppm}$, indicating the purity is not as good as P-APPO-2. Generally, conventional biphenol-based benzoxazines often need extraction procedures to remove insoluble oligomer and unreacted monomers. However, no extraction or purification is required to prepare benzoxazines with moderate-to-high purity by these two approaches.

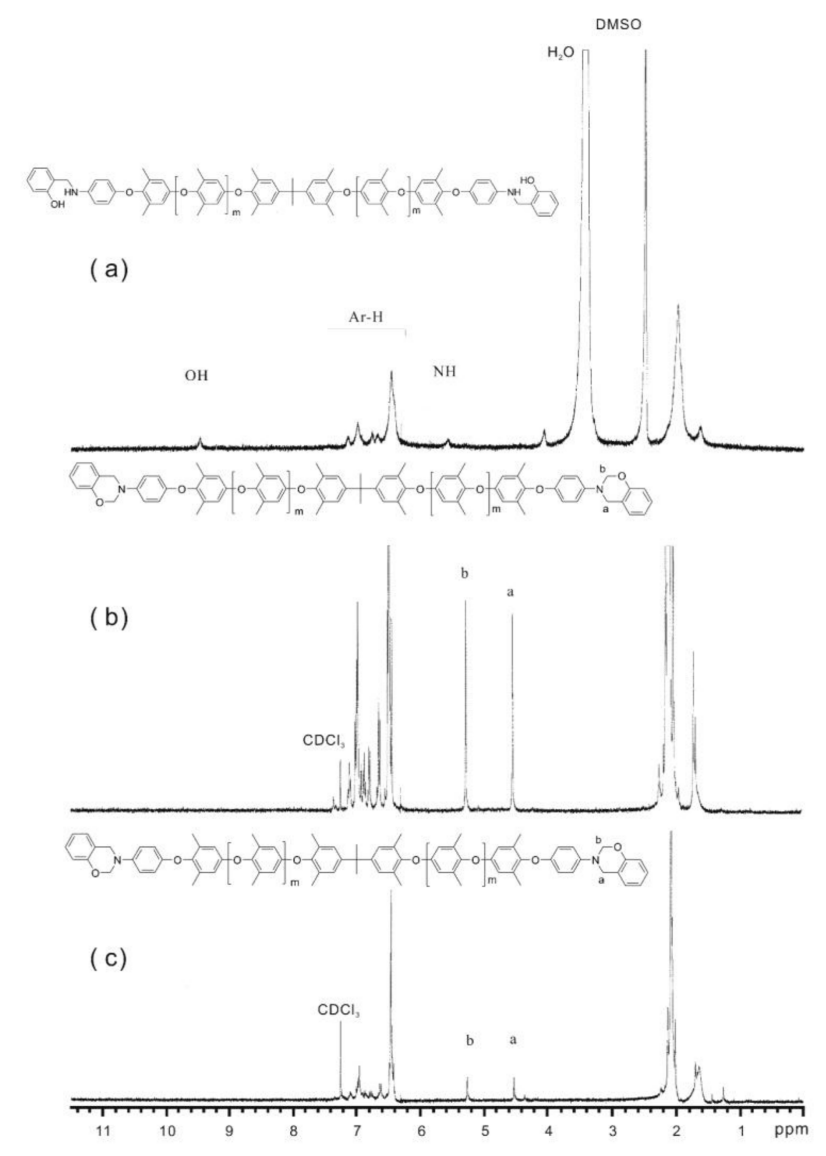

Figure 4. ${ }^{1} \mathrm{H}-\mathrm{NMR}$ spectra of (a) intermediate II in DMSO- $d_{6}$, (b) P-APPO-2, and (c) P-APPO-1 in $\mathrm{CDCl}_{3}$.

\subsection{Synthesis and Characterization of Benzoxazine BPA-APPO}

The main-chain type benzoxazine polymer (BPA-APPO) was prepared by one-pot, Mannich condensation of bisphenol A, APPO, and formaldehyde (Scheme 4) using toluene/ethanol as a solvent, which is recommended by our previous work [39]. Figure 5 shows the ${ }^{1} \mathrm{H}-\mathrm{NMR}$ spectrum of BPA-APPO. The characteristic peaks of oxazine at 5.2 and $4.5 \mathrm{ppm}$ confirm the formation of benzoxazines. The number average molecular weight is $12,200 \mathrm{~g} / \mathrm{mol}$, and the weight average 
molecular weight is $19,800 \mathrm{~g} / \mathrm{mol}$. No signal corresponding to $\mathrm{N}-\mathrm{CH}_{2}-\mathrm{Ph}$ at around $3.80 \mathrm{ppm}$ resulting from the ring-opened structure was observed, revealing the purity of synthesized BPA-APPO.

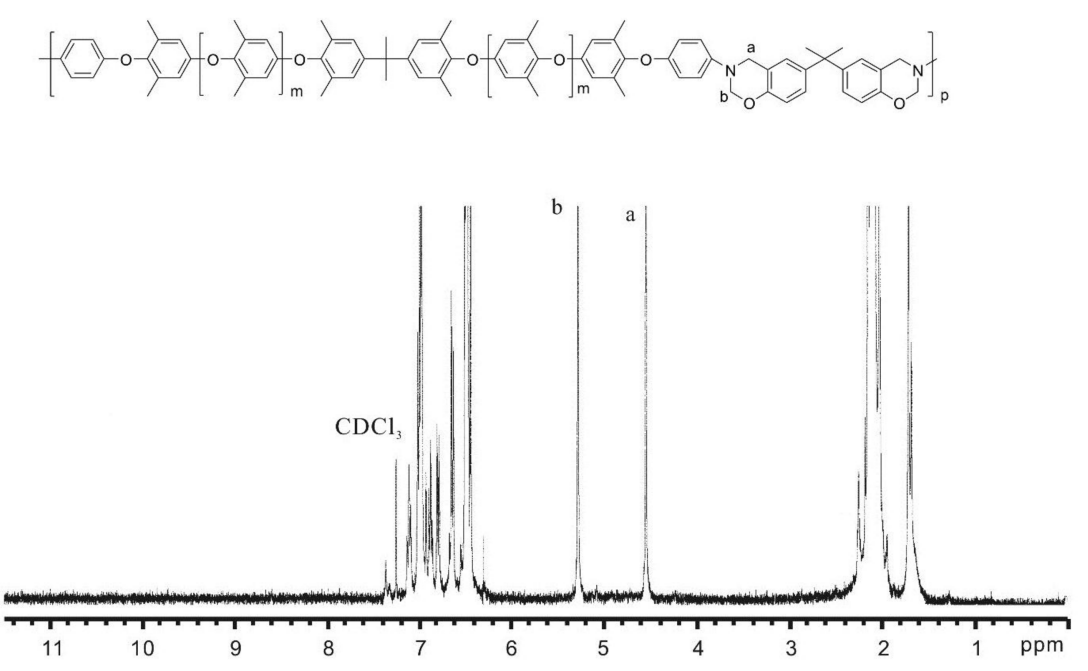

Figure 5. ${ }^{1} \mathrm{H}-\mathrm{NMR}$ spectrum of BPA-APPO in $\mathrm{CDCl}_{3}$.

\subsection{Solubility}

Table 1 lists the solubility data of SA90, P-APPO-1, P-APPO-2, and BPA-APPO. The benzoxazines show good solubility in various solvents except for DMSO. Especially, the main-chain type BPA-APPO also show the same solubility as telechelic oligomer-type P-APPO. The good solubility makes the benzoxazines readily for solution process in the copper clad laminate industry.

Table 1. Solubility data of SA90, P-APPO-1, P-APPO-2, and BPA-APPO.

\begin{tabular}{|c|c|c|c|c|c|c|c|c|c|c|c|}
\hline Sample ${ }^{a}$ & NMP & DMSO & DMAc & DMF & MEK & THF & M-Cresol & Xylene & Toluene & $\mathrm{CH}_{2} \mathrm{Cl}_{2}$ & $\mathrm{CHCl}_{3}$ \\
\hline SA90 & $++^{b}$ & +- & ++ & ++ & ++ & ++ & $+\mathrm{h}$ & ++ & ++ & ++ & ++ \\
\hline P-APPO-2 & ++ & - & ++ & ++ & ++ & ++ & $+\mathrm{h}$ & ++ & ++ & ++ & ++ \\
\hline P-APPO-1 & ++ & - & ++ & ++ & ++ & ++ & $+\mathrm{h}$ & ++ & ++ & ++ & ++ \\
\hline ВРA-АРPO & ++ & - & ++ & ++ & ++ & ++ & $+\mathrm{h}$ & ++ & ++ & ++ & ++ \\
\hline
\end{tabular}

${ }^{a}$ solubility was tested with a $5 \mathrm{mg}$ in $1 \mathrm{~mL}$ of solvent. ${ }^{\mathrm{b}}++$, soluble at room temperature; $+\mathrm{h}$, soluble on heating;

+- , partially soluble on heating; - , insoluble on heating.

\subsection{DSC Thermograms}

Figure 6 shows the DSC thermograms of three PPO-containing benzoxazines and the benzoxazine/HP7200 blends. The exothermic peak temperature is around $270{ }^{\circ} \mathrm{C}$ for PPO-containing benzoxazines. The order of exothermic enthalpy is P-APPO- $1<$ BPA-APPO $<$ P-APPO- 2 . The exothermic enthalpy of P-APPO-2 is more obvious than that of P-APPO-1, probably due to the higher purity of P-APPO-2 (Some ring-opened structures existed in the P-APPO-1, as supported by $4.3 \mathrm{ppm}$ in Figure 4c, so the exothermic enthalpy of P-APPO- 1 is smaller than P-APPO-2). BPA-APPO also displays relatively high purity, as supported by no ring-opened structure in Figure 5. However, the steric hindrance of polymer chains may hinder the access of benzoxazines, so its exothermic enthalpy is slightly lower than that of P-APPO-2. The exothermic peak temperature is around $260{ }^{\circ} \mathrm{C}$ for benzoxazine/HP7200 blend. In a single component system, it is well known that ring opening of oxazines leads to benzoxazine thermosets. However, in the benzoxazine/HP7200 blend system, the reaction routes become more complicated. According to the literature, there are several possible reaction routes might occur [40]. (1) The thermally-induced ring-opening polymerization of benzoxazines. (2) The homopolymerization of epoxy resin catalyzed by tertiary amine moiety in 
benzoxazine. (3) The co-reaction between epoxy and the phenolic $\mathrm{OH}$ resulting from ring-opening of benzoxazine. (4) The ring opening of benzoxazine catalyzed by the alkoxy anion, which is induced by the reaction between tertiary amine and epoxy moiety. This is probably the reason why the exothermic peaks of benzoxazine/HP7200 blend are slightly lower than those of neat benzoxazines. The order of exothermic enthalpy is P-APPO-1/HP7200 blend < BPA-APPO/HP7200 blend < P-APPO-2//HP7200 blend. The purity of benzoxazines and the mobility of molecules that determine the order of exothermic enthalpy in neat benzoxazine system explain the order of exothermic enthalpy in the benzoxazine/HP7200 system.

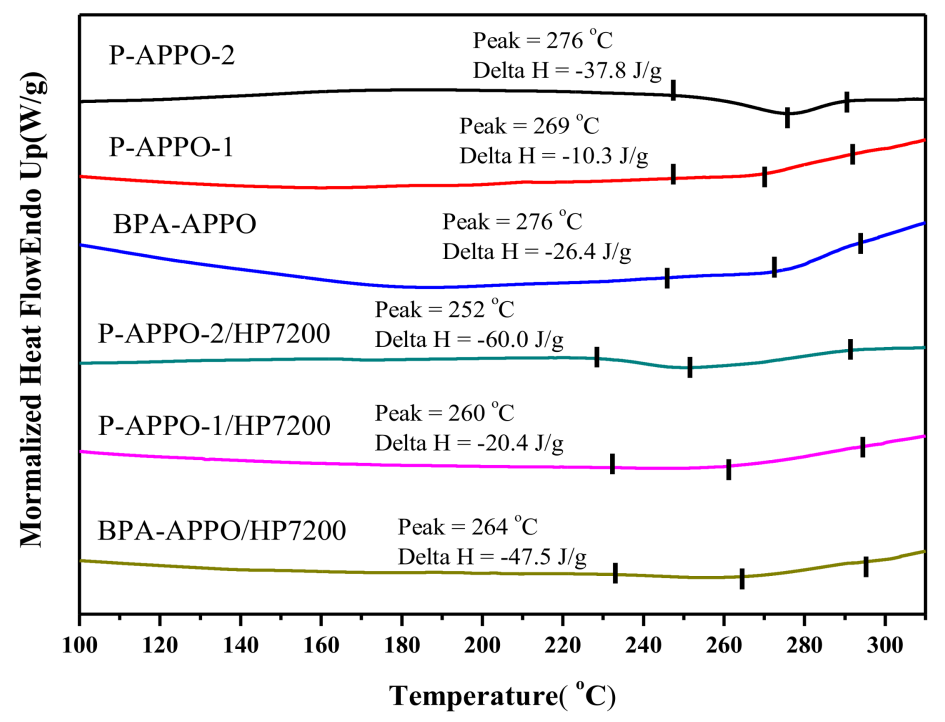

Figure 6. DSC thermograms of three PPO-containing benzoxazines and the benzoxazine/HP7200 blends.

\subsection{Thermal Properties}

Figure 7 shows DMA thermograms of the prepared thermosets. The $T_{\mathrm{g}}$ data are listed in Table 2. The order of $T_{\mathrm{g}}$ value is C-BPA-APPO $\left(225^{\circ} \mathrm{C}\right.$ for $)>$ C-P-APPO-2 $\left(222^{\circ} \mathrm{C}\right)>\mathrm{C}$-P-APPO-1 $\left(218^{\circ} \mathrm{C}\right)$.

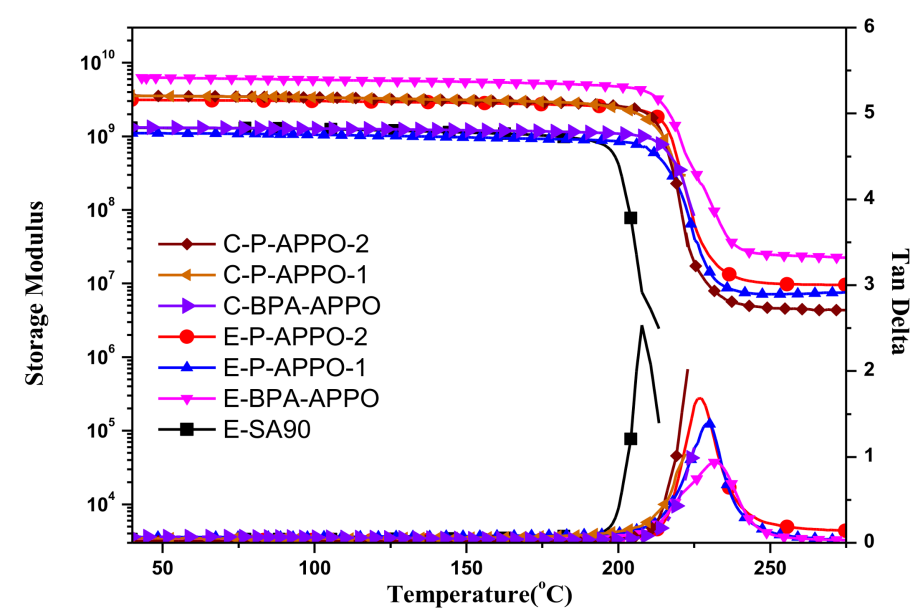

Figure 7. DMA thermograms of the prepared thermosets. 
Table 2. Thermal properties of the resulting polybenzoxazine.

\begin{tabular}{|c|c|c|c|c|c|}
\hline Sample ID & $T_{\mathrm{g}}\left({ }^{\circ} \mathrm{C}\right)(\mathrm{DMA})^{\mathrm{a}}$ & $T_{\mathrm{g}}\left({ }^{\circ} \mathrm{C}\right)(\mathrm{TMA})^{\mathrm{b}}$ & $\mathrm{CTE}\left(\mathrm{ppm} /{ }^{\circ} \mathrm{C}\right)^{\mathrm{c}}$ & $T_{\mathrm{d} 5 \%}\left({ }^{\circ} \mathrm{C}\right)^{\mathrm{d}}$ & CR (\%) ${ }^{\mathrm{e}}$ \\
\hline C-P-APPO-2 & 222 & 194 & 60 & 443 & 28 \\
\hline C-P-APPO-1 & 218 & 185 & 56 & 442 & 28 \\
\hline C-BPA-APPO & 225 & 197 & 60 & 437 & 28 \\
\hline E-P-APPO-2 & 230 & 195 & 71 & 435 & 22 \\
\hline E-P-APPO-1 & 227 & 185 & 75 & 430 & 22 \\
\hline E-BPA-APPO & 232 & 203 & 66 & 433 & 21 \\
\hline E-SA90 & 207 & 174 & 70 & 416 & 22 \\
\hline
\end{tabular}

${ }^{\text {a }}$ Measured by DMA at heating rate of $5{ }^{\circ} \mathrm{C} / \mathrm{min} ; T_{\mathrm{g}}$ value is determined from a peak temperature of the $\tan \delta$ curve. ${ }^{\mathrm{b}}$ Measured by TMA at heating rate of $5{ }^{\circ} \mathrm{C} / \mathrm{min} ; T_{\mathrm{g}}$ value is determined from onset temperature. ${ }^{\mathrm{c}}$ Coefficient of thermal expansion, recorded at 50 to $150{ }^{\circ} \mathrm{C}$. ${ }^{\mathrm{d}}$ Temperatures corresponding to $5 \%$ weight loss by thermogravimetry at a heating rate of $20^{\circ} \mathrm{C} / \mathrm{min}$ in nitrogen. ${ }^{e}$ Residual weight $\%$ at $800^{\circ} \mathrm{C}$ in nitrogen.

In our previous work [41], we report the $T_{\mathrm{g}}$ value of a benzoxazine increases obviously with its molecular weight, but will level off after the molecular weight reaches a certain value. This explains the $T_{\mathrm{g}}$ value of C-BPA-APPO is only slightly higher than C-P-APPO since P-APPO is a telechelic oligomer benzoxazine, not a monomer-type benzoxazine. The higher $T_{\mathrm{g}}$ value of P-APPO-2 than that of P-APPO-1 is probably related to the larger exothermic enthalpy of P-APPO-2 that leads to a complete network. Generally, thermosets of bisphenol A/aniline-based poly(B-a), and bisphenol $\mathrm{F} /$ aniline-based poly(F-a) exhibit a $T_{\mathrm{g}}$ value at around $150-160{ }^{\circ} \mathrm{C}[1,3]$. The values of 218 and $222{ }^{\circ} \mathrm{C}$ are relatively high compared with other benzoxazines, and demonstrate the high- $T_{\mathrm{g}}$ characteristic of PPO-containing benzoxazine thermosets. Table 2 also lists $T_{\mathrm{g}}$ data of the benzoxazine/epoxy thermosets. BPA-APPO/HP7200 (E-BPA-APPO) shows the highest $T_{\mathrm{g}}$ value of $232{ }^{\circ} \mathrm{C}$ while SA90/HP7200 (E-SA90) shows the lowest $T_{\mathrm{g}}\left(207^{\circ} \mathrm{C}\right)$. E-P-APPO-2 and E-P-APPO-1 display higher $T_{\mathrm{g}}$ than E-SA90. The order of modulus of benzoxazine/HP7200 thermosets is E-BPA-APPO > E-P-APPO-2 $>$ E-P-APPO-1 > E-SA90. The order of modulus is the same as that in $T_{\mathrm{g}}$. E-BPA-APPO shows higher modulus value while E-SA90 also shows the lowest modulus, demonstrating that our work is a successful approach to enhancing thermal properties.

Figure 8 shows TMA thermograms of the prepared thermosets. The data of $T_{\mathrm{g}}$ and coefficient of thermal expansion (CTE) are listed in Table 2. The $T_{\mathrm{g}}$ values defined by TMA are $20-30{ }^{\circ} \mathrm{C}$ lower than those defined by DMA, but the trend is the same. The CTE values of thermosets of PPO-containing benzoxazines are around $56-60 \mathrm{ppm} /{ }^{\circ} \mathrm{C}$, which are $10 \mathrm{ppm} /{ }^{\circ} \mathrm{C}$ lower than those of benzoxazine/HP7200 thermosets.

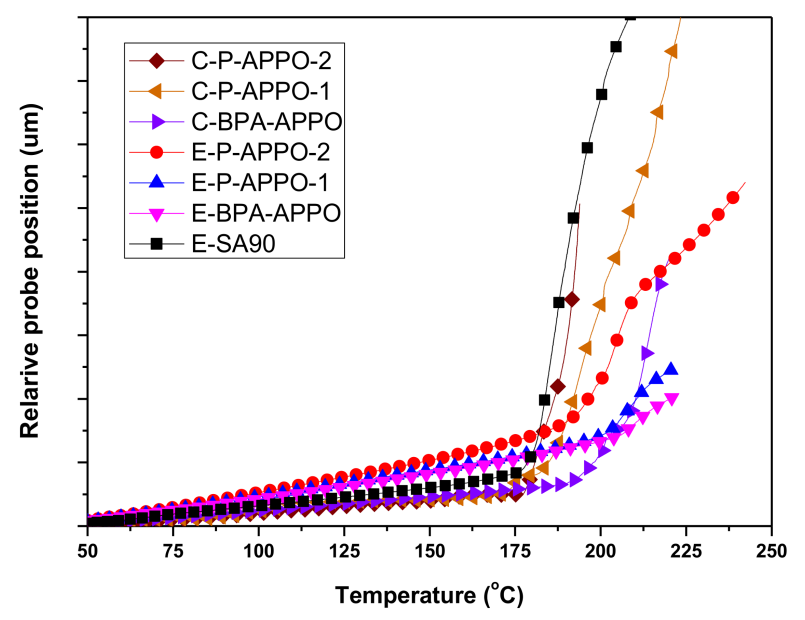

Figure 8. TMA thermograms of the prepared thermosets.

Table 2 lists the thermal stability data of the prepared thermosets in a nitrogen atmosphere. The $5 \mathrm{wt} \%$ decomposition temperature is higher than $430{ }^{\circ} \mathrm{C}$, and char yield at $800{ }^{\circ} \mathrm{C}$ is higher 
than $21 \%$. Generally, the thermosets of bisphenol F/aniline-based and bisphenol A/aniline-based benzoxazines exhibit $5 \mathrm{wt} \%$ decomposition temperature at around $300-350{ }^{\circ} \mathrm{C}[1,3]$. The result demonstrates the high thermal stability characteristic of the thermosets prepared in this work.

\subsection{Dielectric Properties}

PPO is known for its moderate-to-low dielectric constant and very low dissipation factor. As a result, low-dissipation copper-clad laminated has prepared from SA9000 (a phenyl methacrylate-terminated PPO oligomer commercialized by SABIC) and OPE-2st (a vinyl benzyl ether-terminated PPO commercialized by MGC). To the best of our knowledge, no benzoxazine-terminated PPO (or PPO-containing benzoxazine) has been reported. Table 3 lists the dielectric properties of the prepared thermosets. All the thermosets show the same dielectric constant of $2.9 \mathrm{U}$, which is a moderate-to-low value compared with other thermosets (around 3.5 for generally epoxy thermosets [42-46]). In particular, they all show an extremely low dissipation factor. The dissipation factor is as low as $0.0040-0.0043 \mathrm{U}$ for thermosets of PPO-containing benzoxazines, and $0.0050-0.0053$ for benzoxazine/HP7200 thermosets. The dissipation factor is as good as that $(0.005 \mathrm{U})$ of thermosets of commercialized OPE-2st by MGC and SA9000 by SABIC [47].

Table 3. Dielectric properties of the prepared thermosets.

\begin{tabular}{ccc}
\hline Sample & $\mathbf{D}_{\mathbf{k}}(\mathbf{1} \mathbf{~ G ~ H z})$ & $\mathbf{D}_{\mathbf{f}} \mathbf{( 1 \mathbf { ~ G ~ H z } )}$ \\
\hline C-P-APPO-2 & $2.9 \pm 0.01$ & $0.0040 \pm 0.00002$ \\
C-P-APPO-1 & $2.9 \pm 0.02$ & $0.0043 \pm 0.00006$ \\
C-BPA-APPO & $2.9 \pm 0.05$ & $0.0040 \pm 0.00005$ \\
E-P-APPO-2 & $2.9 \pm 0.05$ & $0.0051 \pm 0.00003$ \\
E-P-APPO-1 & $2.9 \pm 0.02$ & $0.0053 \pm 0.00006$ \\
E-BPA-APPO & $2.9 \pm 0.03$ & $0.0050 \pm 0.00006$ \\
E-SA90 & $3.0 \pm 0.02$ & $0.0060 \pm 0.00001$ \\
\hline
\end{tabular}

\section{Conclusions}

There are no free ortho positions for Mannich condensation in the phenolic hydroxyl-end capped oligo (2,6-dimethyl phenylene oxide), making it impossible to perform Mannich condensation directly. To the best of our knowledge, no PPO-containing benzoxazine has been reported before. To prepare the PPO-containing benzoxazine, we first transformed the phenolic hydroxyls to amino groups by a two-step procedure to obtain the amine end-capped oligo (2,6-dimethyl phenylene oxide) (APPO). Based on APPO, a telechelic oligomer-type benzoxazine and a main-chain type benzoxazine polymer (BPA-APPO) were prepared. The telechelic oligomer-type benzoxazine was prepared by a two-pot procedure (for P-APPO-2) and a one-pot procedure (for P-APPO-1). The former has higher purity than the latter, according to NMR and DSC data. Thermosets cured from BPA-APPO has the highest $T_{\mathrm{g}}\left(225^{\circ} \mathrm{C}\right.$ for C-BPA-APPO). The thermoset of P-APPO-2 show slightly higher $T_{\mathrm{g}}$ and lower $D_{\mathrm{f}}$ than that of P-APPO-1, indicating the purity of benzoxazine has an influence on thermal and dielectric properties. BPA-APPO/HP7200 (E-BPA-APPO) shows the highest $T_{\mathrm{g}}$ value of $232{ }^{\circ} \mathrm{C}$ while SA90/HP7200 (E-SA90) shows the lowest $T_{\mathrm{g}}\left(207^{\circ} \mathrm{C}\right)$. E-P-APPO-2 and E-P-APPO-1 display higher $T_{\mathrm{g}}$ and lower $D_{\mathrm{f}}$ than E-SA90, demonstrating that our approach is a successful modification in simultaneously enhancing the thermal and dielectric properties. The $5 \mathrm{wt} \%$ decomposition temperatures of these thermosets are higher than $430{ }^{\circ} \mathrm{C}$, and char yields at $800{ }^{\circ} \mathrm{C}$ are higher than $21 \%$. The dissipation factor is as low as $0.0040-0.0043 \mathrm{U}$ for thermosets of PPO-containing benzoxazines, and $0.0050-0.0053$ for benzoxazine/HP7200 thermosets. The dissipation factor is as good as that $(0.005 \mathrm{U})$ of thermosets of commercialized OPE-2st by MGC and SA9000 by SABIC. The combination of high $T_{\mathrm{g}}$ characteristic, high $T_{\mathrm{d}}$ characteristic, moderate-to-low $D_{\mathrm{k}}$, and extremely low dissipation factor makes the PPO-containing benzoxazine attractive for printed circuit boards for applications in high-frequency communication. 
Acknowledgments: Financial support of this work from the Ministry of Science and Technology (104-2628-E-005 -002 -MY3), Taiwan is highly appreciated.

Author Contributions: Ching-Hsuan Lin conceived and designed the experiments; Kuan-Wei Lee performed the experiments; Chien-Han Chen and Tzong-Yuan Juang analyzed the data; and Ching-Hsuan Lin wrote the paper.

Conflicts of Interest: The authors declare no conflict of interest.

\section{References}

1. Ning, X.; Ishida, H. Phenolic materials via ring-opening polymerization: Synthesis and characterization of bisphenol-a based benzoxazines and their polymers. J. Polym. Sci. Part A Polym. Chem. 1994, 32, 1121-1129. [CrossRef]

2. Ohashi, S.; Cassidy, F.; Huang, S.; Chiou, K.; Ishida, H. Synthesis and ring-opening polymerization of 2-substituted 1,3-benzoxazine: The first observation of the polymerization of oxazine ring-substituted benzoxazines. Polym. Chem. 2016, 7,7177-7184. [CrossRef]

3. Liu, J.; Ishida, H. Anomalous isomeric effect on the properties of bisphenol f-based benzoxazines: Toward the molecular design for higher performance. Macromolecules 2014, 47, 5682-5690. [CrossRef]

4. Yagci, Y.; Kiskan, B.; Ghosh, N.N. Recent advancement on polybenzoxazine-A newly developed high performance thermoset. J. Polym. Sci. Part A Polym. Chem. 2009, 47, 5565-5576. [CrossRef]

5. Ghosh, N.N.; Kiskan, B.; Yagci, Y. Polybenzoxazines-New high performance thermosetting resins: Synthesis and properties. Prog. Polym. Sci. 2007, 32, 1344-1391. [CrossRef]

6. Endo, T. Toward elucidating the role of number of oxazine rings and intermediates in the benzoxazine backbone on their thermal characteristics. Macromolecules 2016, 49, 8466-8478.

7. Baranek, A.D.; Kendrick, L.L.; Narayanan, J.; Tyson, G.E.; Wand, S.; Patton, D.L. Flexible aliphatic-bridged bisphenol-based polybenzoxazines. Polym. Chem. 2012, 3, 2892-2900. [CrossRef]

8. Rodriguez Arza, C.; Froimowicz, P.; Ishida, H. Smart chemical design incorporating umbelliferone as natural renewable resource toward the preparation of thermally stable thermosets materials based on benzoxazine chemistry. RSC Adv. 2015, 5, 97855-97861. [CrossRef]

9. Ye, Y.S.; Huang, Y.J.; Chang, F.C.; Xue, Z.G.; Xie, X.L. Synthesis and characterization of thermally cured polytriazole polymers incorporating main or side chain benzoxazine crosslinking moieties. Polym. Chem. 2014, 5, 2863-2871. [CrossRef]

10. Lligadas, G.; Tuzun, A.; Ronda, J.C.; Galia, M.; Cadiz, V. Polybenzoxazines: New players in the bio-based polymer arena. Polym. Chem. 2014, 5, 6636-6644. [CrossRef]

11. Wang, H.; Zhu, R.; Yang, P.; Gu, Y. A study on the chain propagation of benzoxazine. Polym. Chem. 2016, 7, 860-866. [CrossRef]

12. Kawaguchi, A.W.; Sudo, A.; Endo, T. Functional 1,3-benzoxazine bearing 4-pyridyl group: Synthesis and thermally induced polymerization behavior. J. Polym. Sci. Part A Polym. Chem. 2014, 52, 410-416. [CrossRef]

13. Arslan, M.; Kiskan, B.; Yagci, Y. Benzoxazine-based thermosets with autonomous self-healing ability. Macromolecules 2015, 48, 1329-1334. [CrossRef]

14. Zhang, S.; Yang, P.; Bai, Y.; Zhou, T.; Zhu, R.; Gu, Y. Polybenzoxazines: Thermal responsiveness of hydrogen bonds and application as latent curing agents for thermosetting resins. ACS Omega 2017, 2, 1529-1534. [CrossRef]

15. Arslan, M.; Kiskan, B.; Yagci, Y. Ring-opening polymerization of 1,3-benzoxazines via borane catalyst. Polymers 2018, 10, 239. [CrossRef]

16. Soto, M.; Hiller, M.; Oschkinat, H.; Koschek, K. Multifunctional benzoxazines feature low polymerization temperature and diverse polymer structures. Polymers 2016, 8, 278. [CrossRef]

17. Hamerton, I.; McNamara, L.T.; Howlin, B.J.; Smith, P.A.; Cross, P.; Ward, S. Examining the initiation of the polymerization mechanism and network development in aromatic polybenzoxazines. Macromolecules 2013, 46, 5117-5132. [CrossRef] [PubMed]

18. Wan Hassan, W.A.; Liu, J.; Howlin, B.J.; Ishida, H.; Hamerton, I. Examining the influence of bisphenol a on the polymerisation and network properties of an aromatic benzoxazine. Polymer 2016, 88, 52-62. [CrossRef]

19. Kim, S.-K.; Choi, S.-W.; Jeon, W.S.; Park, J.O.; Ko, T.; Chang, H.; Lee, J.-C. Cross-linked benzoxazine-benzimidazole copolymer electrolyte membranes for fuel cells at elevated temperature. Macromolecules 2012, 45, 1438-1446. [CrossRef] 
20. Ishida, H.; Allen, D.J. Physical and mechanical characterization of near-zero shrinkage polybenzoxazines. J. Polym. Sci. Part B Polym. Phys. 1996, 34, 1019-1030. [CrossRef]

21. Wang, C.F.; Su, Y.C.; Kuo, S.W.; Huang, C.F.; Sheen, Y.C.; Chang, F.C. Low-surface-free-energy materials based on polybenzoxazines. Angew. Chem. Int. Ed. 2006, 45, 2248-2251. [CrossRef] [PubMed]

22. Su, Y.-C.; Chang, F.-C. Synthesis and characterization of fluorinated polybenzoxazine material with low dielectric constant. Polymer 2003, 44, 7989-7996. [CrossRef]

23. Tseng, M.-C.; Liu, Y.-L. Preparation, morphology, and ultra-low dielectric constants of benzoxazine-based polymers/polyhedral oligomeric silsesquioxane (poss) nanocomposites. Polymer 2010, 51, 5567-5575. [CrossRef]

24. Zhang, K.; Zhuang, Q.; Liu, X.; Cai, R.; Yang, G.; Han, Z. Synthesis and copolymerization of benzoxazines with low-dielectric constants and high thermal stability. RSC Adv. 2013, 3, 5261-5270. [CrossRef]

25. Zhang, K.; Zhuang, Q.; Zhou, Y.; Liu, X.; Yang, G.; Han, Z. Preparation and properties of novel low dielectric constant benzoxazole-based polybenzoxazine. J. Polym. Sci. Part A Polym. Chem. 2012, 50, 5115-5123. [CrossRef]

26. Vengatesan, M.R.; Devaraju, S.; Dinakaran, K.; Alagar, M. Sba-15 filled polybenzoxazine nanocomposites for low-k dielectric applications. J. Mater. Chem. 2012, 22, 7559-7566. [CrossRef]

27. Velez-Herrera, P.; Doyama, K.; Abe, H.; Ishida, H. Synthesis and characterization of highly fluorinated polymer with the benzoxazine moiety in the main chain. Macromolecules 2008, 41, 9704-9714. [CrossRef]

28. Lin, C.H.; Chang, S.L.; Lee, H.H.; Chang, H.C.; Hwang, K.Y.; Tu, A.P.; Su, W.C. Fluorinated benzoxazines and the structure-property relationship of resulting polybenzoxazines. J. Polym. Sci. Part A Polym. Chem. 2008, 46, 4970-4983. [CrossRef]

29. Hay, A.S. Poly(phenylene oxides)s and poly(arylene ether)s derived from 2,6-diarylphenols. Prog. Polym. Sci. 1999, 24, 45-80. [CrossRef]

30. Hay, A.S.; Blanchard, H.S.; Endres, G.F.; Eustance, J.W. Polymerization by oxidative coupling. J. Am. Chem. Soc. 1959, 81, 6335-6336. [CrossRef]

31. Nunoshige, J.; Akahoshi, H.; Shibasaki, Y.; Ueda, M. Efficient oxidative coupling polymerization for synthesis of thermosetting poly(phenylene ether) copolymer with a low dielectric loss. J. Polym. Sci. Part A Polym. Chem. 2008, 46, 5278-5282. [CrossRef]

32. Fukuhara, T.; Shibasaki, Y.; Ando, S.; Ueda, M. Synthesis of thermosetting poly(phenylene ether) containing allyl groups. Polymer 2004, 45, 843-847. [CrossRef]

33. White, D.M. Polymerization by oxidative coupling. Ii. Co-redistribution of poly(2,6-diphenyl-1,4-phenylene ether) with phenols. J. Polym. Sci. Part A-1 Polym. Chem. 1971, 9, 663-675. [CrossRef]

34. White, D.M. Reactions of poly(phenylene oxide)s with quinones. I. The quinone-coupling reaction between low-molecular-weight poly(2,6-dimethyl-1,4-phenylene oxide) and 3,3',5,5'-tetramethyl-4,4'-diphenoquinone. J. Polym. Sci. Polym. Chem. Ed. 1981, 19, 1367-1383. [CrossRef]

35. White, D.M. Synthesis of 4-hydroxyarylene ethers by the equilibration of phenols with poly(2,6-dimethyl-1,4-phenylene ether). J. Org. Chem. 1969, 34, 297-303. [CrossRef]

36. Jayakannan, M.; Smitha, T.R. Synthesis and characterization of new telechelic poly(phenyleneoxide)s. Eur. Polym. J. 2004, 40, 1169-1175. [CrossRef]

37. Tingerthal, J.M.; Nava, H.; Percec, V. Synthesis and characterization of aba triblock copolymers containing poly(2,6-dimethyl-1,4-phenylene oxide) as a blocks and tetramethyl bisphenol-a polysulfone as b blocks. J. Polym. Sci. Part A Polym. Chem. 1987, 25, 2043-2062. [CrossRef]

38. Lin, C.H.; Chang, S.L.; Hsieh, C.W.; Lee, H.H. Aromatic diamine-based benzoxazines and their high performance thermosets. Polymer 2008, 49, 1220-1229. [CrossRef]

39. Lin, C.H.; Chang, S.L.; Shen, T.Y.; Shih, Y.S.; Lin, H.T.; Wang, C.F. Flexible polybenzoxazine thermosets with high glass transition temperatures and low surface free energies. Polym. Chem. 2012, 3, 935-945. [CrossRef]

40. Zhao, P.; Zhou, Q.; Liu, X.; Zhu, R.; Ran, Q.; Gu, Y. Phase separation in benzoxazine/epoxy resin blending systems. Polym. J. 2012, 45, 637. [CrossRef]

41. Wang, M.W.; Jeng, R.J.; Lin, C.H. The robustness of a thermoset of a main-chain type polybenzoxazine precursor prepared through a strategy of a-a and b-b polycondensation. RSC Adv. 2016, 6, 18678-18684. [CrossRef]

42. Tao, Z.; Yang, S.; Ge, Z.; Chen, J.; Fan, L. Synthesis and properties of novel fluorinated epoxy resins based on 1,1-bis(4-glycidylesterphenyl)-1-(3'-trifluoromethylphenyl)-2,2,2-trifluoroethane. Eur. Polym. J. 2007, 43, 550-560. [CrossRef] 
43. Zhao, X.-Y.; Liu, H.-J. Review of polymer materials with low dielectric constant. Polym. Int. 2010, 59, 597-606. [CrossRef]

44. Lin, C.H.; Jiang, Z.R.; Wang, C.S. Low dielectric thermoset. Ii. Synthesis and properties of novel 2,6-dimethyl phenol-dipentene epoxy. J. Polym. Sci. Part A Polym. Chem. 2002, 40, 4084-4097. [CrossRef]

45. Lin, C.H.; Hsiao, C.N.; Li, C.H.; Wang, C.S. Low dielectric thermoset. Iv. Synthesis and properties of a dipentene-containing cyanate ester and its copolymerization with bisphenol a dicyanate ester. J. Polym. Sci. Part A Polym. Chem. 2004, 42, 3986-3995. [CrossRef]

46. Cai, S.X.; Lin, C.H. Flame-retardant epoxy resins with high glass-transition temperatures from a novel trifunctional curing agent: Dopotriol. J. Polym. Sci. Part A Polym. Chem. 2005, 43, 2862-2873. [CrossRef]

47. Ishii, K.; Norisue, Y.; Ohno, D.; Miyamoto, M. Vinyl Compound and Cured Product Thereof. U.S. Patent US 6,995,195 B992, 25 July 2006.

(C) 2018 by the authors. Licensee MDPI, Basel, Switzerland. This article is an open access article distributed under the terms and conditions of the Creative Commons Attribution (CC BY) license (http:/ / creativecommons.org/licenses/by/4.0/). 